\title{
Probing the Psychosocial Correlates of Unintentional Injuries Among Grade-School Children: A Comparison of Urban and Migrant Students in China
}

\author{
Chao Gao ${ }^{1} \cdot$ Pengfei Chai ${ }^{2} \cdot$ Jingjing $\mathrm{Lu}^{1} \cdot$ Hongmei Wang ${ }^{1} \cdot \mathrm{Lu} \mathrm{Li}^{1} \cdot$ Xudong Zhou $^{1}$
}

Published online: 31 March 2019

(c) The Author(s) 2019

\begin{abstract}
Objective To assess the prevalence and characteristics of unintentional injuries among 5 to 9 grades students for both urban and migrant children groups, and probe the major socio-demographic and psychosocial risk factors.

Methods A cross-sectional survey was conducted from May to June in 2013 with 2266 urban and 1770 migrant children among 5 to 9 grades from 13 schools in Yinzhou, Southeast China. Unintentional injuries and psychosocial factors were measured via self-administered questionnaires. Descriptive statistics and binary logistic regression were employed in data analysis.

Results The annual prevalence of unintentional injury in the past year was 38\%. Compared with urban children, migrant children reported lower prevalence of sprains/fractures (15.5 vs. 18.7\%), but higher in animal bites (15.7 vs. 9.6\%), burns (20.7 vs. $16 \%$ ), nonfatal drowning (6 vs. $2.7 \%$ ), and unintentional injury (40.9 vs. $35.7 \%)$. Binary logistic regression analysis revealed that male, young age, attending migrant children school, scoring high in emotional symptoms, conduct problems or hyperactivity, with suicide ideation, and experiencing verbal maltreatment were associated with unintentional injury incidence in the past 12 months.

Conclusions The annual prevalence of unintentional injury among 5 to 9 grades schoolchildren in Yinzhou was high. Child unintentional injuries were associated with multi-level psychosocial factors. Although the direct correlation between migrant status and unintentional injuries was unobserved, migration could have an indirect relationship with injury. The findings could inform some implications for prevention strategies in urban area.
\end{abstract}

Keywords Unintentional injury $\cdot$ Mental health $\cdot$ Child maltreatment $\cdot$ Migrant children $\cdot$ China

Unintentional injury has been recognized as a pervasive challenge in public health, raising great concern globally (Chandran et al. 2010; de Ramirez et al. 2012). A previous study estimated a nationwide injury death rate of 65 per 100000 population in China (Wang et al. 2008), which was

$\mathrm{Lu} \mathrm{Li}$

lilu@zju.edu.cn

Xudong Zhou

zhouxudong@zju.edu.cn

1 The Institute of Social and Family Medicine, School of Medicine, Zhejiang University, 866 Yuhangtang Rd., Hangzhou, Zhejiang 310058, P. R. China

2 Faculty of Yinzhou District CDC, 1221 Xueshi Rd. Yinzhou, Ningbo 315199, P. R. China almost twice compared with the rates reported from US and most other developed countries (Hu and Baker 2009; WHO 2008). Children and adolescents' physical functions and behavior patterns differ from adults, thus they are more vulnerable to unintentional injuries (Ameratunga and Peden 2009). As estimated by the global burden of disease (GBD) studies, unintentional injuries among 1 to 19-year-olds accounted for $12 \%$ of 5.1 million global deaths from injuries in 2010 (Lozano et al. 2012). Additionally, unintentional injuries are a major cause of disabilities, which have a long-lasting impact on children's lives, relationships with peers and learning. In China, the proportion of injury among all deaths in children aged 0-14 years had increased from $18.69 \%$ in 2004 to $21.26 \%$ in 2011 (Yin et al. 2015). In 2011, China has released the Outline Program for Development of Children (2011-2020), incorporating an 
ambitious goal that the injury mortality among children under 18 should be reduced by one-sixth by 2020 .

Previous studies have demonstrated the profile of unintentional injuries among children and adolescents. The prevalence of unintentional injuries during the past 12 months was $17.3 \%$ in Europe (Keyes et al. 2014), 24\% in Canada (Gilbride et al. 2006), 33.9\% in Jordan (ALBashtawy et al. 2016), 48\% in Yemen (Alshahethi 2014), and $46.8 \%$ in Thailand (Peltzer and Pengpid 2012). The most common injuries were dislocations and sprains, open wounds, and superficial injuries and contusions (Spady et al. 2004); Falls, animal bites, traffic accidents, and burns were leading causes of these injuries (Bhamkar et al. 2016; Peltzer and Pengpid 2017).

The past four decades have witnessed a dramatic economic boom along with a great internal migration for jobs from rural inland to coastal urban regions in China. The "migrant population" mentioned here is defined as individuals leaving their residences for cities for more than six months without changing their household registration (hukou) (Ji et al. 2016). Unlike the transnational immigrants discussed in numerous western studies, usually the Chinese rural to urban migrant workers do not face challenging acculturation (Schwartz et al. 2010), because cities in China provide a relatively homogeneous environment with no race barriers, and almost no religious barriers to their cultural adjusting (Yue et al. 2013). However, migrant workers at large are marginalized in various urban welfare schemes. The structural exclusion is particularly based on the special urban-rural dualistic household registration system. The offsprings of migrant workers are assigned a rural hukou registration along with their parents, which means the inequity in life opportunities between rural and urban residents remains in future generations. There were 35.8 million migrant children aged $0-17$ according to the latest national census in 2010, among which about 15 million children were in the age range of compulsory education mandate (Liang 2016), presenting a substantial segment of urban inhabitants.

There has been growing attention to migrant children on diverse sociological issues. Compared with their nonmigrant peers, migrant children were more prone to meet developmental challenges such as individual motor impairment (Jin et al. 2016), low school achievement (Luo and Zhang 2017) and child maltreatment (Gao et al. 2017). However, previous studies mainly focused on the relationship between psychologic and pedagogic outcomes and migrant status, whilst unintentional injuries of migrant children at school age as a public health concern were still underrepresented in the literature.

In China, migration has laid an overall impact on migrant children's life. As children migrate to temporary urban residence with their parents, the original social security network based on kinship in their rural community has been split up. However, like their fathers, they also suffer from multiple structural exclusion in the cities so that they have to difficultly face with the adjustments and challenges in family, life, and study (Liu et al. 2014). Migration also breaks down the structure and then destructs the functions of family. A substantial portion of migrant children live with one parent in urban settlement, resulting in the child neglect and absence of parental care (Xu and Xie 2015). Moreover, the migrant children schools are marginalized in the urban education system, and they tend to have inexperienced teachers and school administrators, crowded classrooms, and inferior facilities (Chen and Feng 2017), children attending these schools can hardly receive adequate hygiene knowledge and safe recreational spaces. These factors together expose migrant children under multiple health risks, including unintentional injuries. Nevertheless, previous studies were limited either to simply assessing the epidemiological features of unintentional injury (Shaohua Li et al. 2013) or to the absence of investigation into children's migrant status (Sun et al. 2006).

The ecological systems theory postulated human behavior as a result of person-environment interaction (Bronfenbrenner 1979). To explain how the inherent qualities of children and their environment interact, it is necessary to take both the macro-level and micro-level environmental variables into account, and analyses of health and factorhealth interactions should address the multidimensional and complex nature of human environments (Stokols 1992). Injuries are a frequent and sometimes devastating outcome of risk taking but are also inherent in the environment in which adolescents live, study, and play (Sleet et al. 2010). The occurrence of unintentional injuries in children is associated with multilevel factors, including but not limited to socioeconomic factors (Gilbride et al. 2006; Simpson et al. 2005), psychological disorders (Asbridge et al. 2014; Chen et al. 2005), risk-taking behavior (Feng et al. 2017), school environment (Fang et al. 2015; ALBashtawy et al. 2016) and parenting style (Keyes et al. 2014). In China, the ecological model has been introduced to estimate the effects of both individual factors and contextual environments on unintentional injuries among children aged 6-16 in Chongqing, a south-western city (Hu et al. 2018). Since children and adolescents spend most of their time at school and home, it is necessary to examine potential psychosocial correlates with unintentional injuries from a socioecological perspective incorporating their individual factors, school factors and family status.

The findings reported in this paper came from a larger project investigating the wellbeing of children dwelling in urban communities. By employing the data from a largescale survey in Yinzhou, China, this study aimed to assess the prevalence and characteristics of unintentional injuries 
among school age students (5 to 9 grades) for both urban and migrant child groups, and explore major socio-demographic and psychosocial risk factors. The exploration of these issues would help to design injury prevention strategies for children and adolescents, especially those with a rural background. Theoretically, we assumed that unintentional injury was not only related with children's individual characteristics, but also school features and family status. Based on the literature review, we proposed the following hypotheses:

First, it was hypothesized that the prevalence of unintentional injuries would be higher among migrant children as opposed to non-migrant urban children (hypothesis 1). Second, it was hypothesized that the occurrence of child unintentional injuries was a health outcome of a multi-level socio-ecological system (hypothesis 2 ). To be specific, on the individual level, migrant children, male, young age, poor mental status and substance use behavior would be positively related with the risks of unintentional injuries (hypothesis 2a); On the school level, attending migrant children school would be positively related with the risks of unintentional injuries (hypothesis 2b); On the family level, bad family socioeconomic status and parental maltreatment would be positively related with the risks of unintentional injuries (hypothesis $2 \mathrm{c}$ ).

\section{Method}

\section{Participants}

A cross-sectional survey was conducted in Yinzhou district of Ningbo, a major port in Southeast China, from May to June in 2013. Ningbo was noticeable for its export-oriented manufacturing industry, attracting large migrant population which made up over $30 \%$ of the 7.6 million resident population.

In this study, children were identified by their household registry, and thereby categorized into urban group (registered in Yinzhou) and migrant group (registered elsewhere). There were two kinds of schools in Yinzhou: public schools which recruit both native urban children and a few migrant children, and migrant children schools, which essentially oriented to migrant children only. About $30 \%$ of migrant children could be enrolled into public schools every year. In order to ensure the comparability of sample size between the two groups, 8 public schools and 5 migrant children schools were randomly selected from the school membership roster to participate in the survey. In each school, students among grades 5-9 and younger than 18 were invited.

Across the 13 schools, a total of 4409 students were enrolled, of which 4217 students completed the questionnaire, yielding a response rate of $95.65 \%$. 181 questionnaires were removed because they contained missing data in all the five injury items, therefore the final sample consisted of 4036 students, including 2266 urban children and 1770 migrant children.

As shown in Tables $1,47.8 \%$ of the children were female. The mean age of the sample was $13.81(\mathrm{SD}=1.39)$. Migrant status was significantly associated with all the socio-demographic variables. The proportion of girls was higher in urban group (50.7 vs. $44.0 \%, p<0.001)$. The mean age of urban group was older than that of migrant group (13.91 vs. $13.68, p<0.001)$. More children in the urban group were attending middle school (78.6 vs. $58.1 \%$, $p<0.001)$. An overwhelming majority $(99.4 \%)$ of urban children were attending public schools, while the proportion in migrant group was $54.7 \%, p<0.001$. The children in urban group reported higher household economic status $(p<0.001)$, higher parents' education level $(p<0.001)$, and higher parental divorce rate ( 6.2 vs. $4.3 \%, p=0.007)$.

\section{Procedure}

Project packs, including an introduction letter and a consent form were distributed to parents by school staff. The selfadministered survey was conducted during the breaks in the classroom where students with completed parental consent were gathered. A brief introduction about the study was given to the students and the questionnaire was filled out by students themselves with necessary assistance provided by research assistants. Teachers were not allowed to enter into the classroom to ensure the anonymity. Data were finally input anonymously.

\section{Measures}

\section{Socio-Demographic Variables}

The questionnaire started with a socio-demographic section to investigate children's individual and family characteristics including gender, age, grade, household registry, household economic status, parents' education attainment and marital status. Household economic status was measured by the number of household items possessed, including air conditioner, refrigerator, washing machine, computer and private car (Kumar et al. 2013), thereby this variable was coded as poor ( 0 to 2 items), fair ( 3 to 4 items), and wealthy (5 items).

\section{Unintentional Injury}

In this study we focused on five causes of injuries: sprains or fractures, animal bites, burns, nonfatal drowning, and traffic accidents, which were reported relatively common (Hyder 2009; ALBashtawy et al. 2016) among children and 
Table 1 Demographic characteristics of the participants by child migrant status

\begin{tabular}{|c|c|c|c|c|c|}
\hline & $\begin{array}{l}\text { Total } \\
n(\%) \\
(n=4036)\end{array}$ & $\begin{array}{l}\text { Urban } \\
n(\%) \\
(n=2266)\end{array}$ & $\begin{array}{l}\text { Migrant } \\
n(\%) \\
(n=1770)\end{array}$ & $\chi^{2} / t$ & $P$-value \\
\hline \multicolumn{6}{|l|}{ Gender } \\
\hline Female & $1928(47.8 \%)$ & $1149(50.7 \%)$ & $779(44.0 \%)$ & \multirow[t]{2}{*}{17.85} & \multirow[t]{2}{*}{$<0.001$} \\
\hline Male & $2108(52.2 \%)$ & $1117(49.3 \%)$ & $991(56.0 \%)$ & & \\
\hline Age $($ mean $\pm s d)$ & $13.81 \pm 1.39$ & $13.91 \pm 1.29$ & $13.68 \pm 1.50$ & 5.000 & $<0.001$ \\
\hline \multicolumn{6}{|l|}{ Grade } \\
\hline $5-6$ & $1227(30.4 \%)$ & $486(21.4 \%)$ & $741(41.9 \%)$ & \multirow[t]{2}{*}{195.8} & \multirow[t]{2}{*}{$<0.001$} \\
\hline $7-9$ & $2809(69.6 \%)$ & $1780(78.6 \%)$ & $1029(58.1 \%)$ & & \\
\hline \multicolumn{6}{|l|}{ School type } \\
\hline Public school & $3221(79.8 \%)$ & $2253(99.4 \%)$ & $968(54.7 \%)$ & \multirow[t]{2}{*}{1234} & \multirow[t]{2}{*}{$<0.001$} \\
\hline Migrant children school & $815(20.2 \%)$ & $13(0.6 \%)$ & $802(45.3 \%)$ & & \\
\hline \multicolumn{6}{|l|}{ Family economic status } \\
\hline Poor & $581(14.6 \%)$ & $48(2.1 \%)$ & $533(30.7 \%)$ & \multirow[t]{3}{*}{990.8} & \multirow[t]{3}{*}{$<0.001$} \\
\hline Fair & $1467(36.8 \%)$ & $682(30.3 \%)$ & $785(45.2 \%)$ & & \\
\hline Wealthy & $1941(48.7 \%)$ & $1523(67.6 \%)$ & $418(24.1 \%)$ & & \\
\hline \multicolumn{6}{|l|}{ Parents' education attainment } \\
\hline Illiteracy/primary school & $381(9.7 \%)$ & $82(3.7 \%)$ & $299(17.4 \%)$ & \multirow[t]{5}{*}{561.9} & \multirow[t]{5}{*}{$<0.001$} \\
\hline Middle school & $1997(50.8 \%)$ & $943(42.6 \%)$ & $1054(61.2 \%)$ & & \\
\hline High school & $1048(26.6 \%)$ & $733(33.1 \%)$ & $315(18.3 \%)$ & & \\
\hline Junior college & $281(7.1 \%)$ & $250(11.3 \%)$ & $31(1.8 \%)$ & & \\
\hline Undergraduate and above & $227(5.8 \%)$ & $205(9.3 \%)$ & $22(1.3 \%)$ & & \\
\hline \multicolumn{6}{|l|}{ Parents' marital status } \\
\hline Divorced & $215(5.4 \%)$ & $140(6.2 \%)$ & $75(4.3 \%)$ & \multirow[t]{2}{*}{7.375} & \multirow[t]{2}{*}{0.007} \\
\hline Non-divorced & $3792(94.6 \%)$ & $2111(93.8 \%)$ & $1681(95.7 \%)$ & & \\
\hline
\end{tabular}

adolescents, using five separate questions (responses were no/yes). Unintentional injury, as the main outcome variable, was coded later into two categories: not injured with any type of injury(0), or experienced at least one episode of injury (1).

\section{Mental Health Status}

The Strengths and Difficulties Questionnaire (SDQ) (Goodman et al. 1998) is a brief and efficient tool to screen child and adolescent mental health. In China, it has proven to have sizable reliability and validity (Du et al. 2008; Yao et al. 2009) among Chinese adolescents in both the public health (Wang et al. 2014; Xiaoli et al. 2014) and clinical context (Mellor et al. 2016). We introduced the Chinese version of the 25-item self-report Strengths and Difficulties Questionnaire (SDQ), which was comprised of four difficulty subscales (emotional symptom, conduct problem, hyperactivity, peer problem), and a prosocial behavior subscale. Five SDQ subscales were accessed to reflect children's mental health status. The cut-off points for abnormal scores for each sub-scale were as follows: emotional symptoms $\geq 7$, conduct problems $\geq 5$, hyperactivity $\geq 7$, peer problems $\geq 6$, and prosocial behaviour $\leq 4$ (Goodman 1997; Kou et al. 2007). In this study, the Cronbach's alpha coefficient of each subscale was 0.76 for emotional symptoms; 0.72 for conduct problems; 0.77 for hyperactivity; 0.67 for peer problems, and 0.79 for prosocial behavior. Suicide ideation, as a potential psychological risk factor on unintentional injury (Peltzer and Pengpid 2017), was assessed by a question: "Did you have suicidal thoughts during the past 2 weeks? The responses "I had thoughts of killing myself" and "I had thoughts of killing myself but I wouldn't carry them out" were identified as a "yes" answer.

\section{Substance Use Behavior}

We assessed two kinds of substance use behavior: current smoking ("Are you currently smoking?") and current alcohol use ("Are you currently drinking wine or alcoholic beverages?"), the response options were "no" and "yes".

\section{Parental Maltreatment}

Two items were utilized to assess if a child was maltreated by his/her parents: verbal maltreatment ("In the past year, 
how often have your parents harshly scolded you?") and physical maltreatment ("In the past year, how often have your parents beaten you by a lash or a stick?"). The response options were "never", "occasionally" and "often".

\section{Data Analyses}

Descriptive statistics of variables of socio-demographic characteristics, unintentional injuries, mental health status, substance use behavior and parental maltreatment were presented with number $(\mathrm{N})$, percentage $(\%)$ and mean \pm standard deviation (SD), as appropriate. Chi-square analysis (for categorical variables) and T-test (for continuous variables) were used to explore the differences between child groups (urban vs. migrant, injured vs. non-injured). Nested binary logistic regression analysis was performed to explore the effects of potential independent variables on unintentional injury. Four blocks of independent variables were successively entered into the model by the following steps: step 1: migrant status; step 2: the other individual factors; step3: school type; step 4: family factors. All statistical analyses were carried out using Statistical Package for the Social Science (Version 20.0; IBM Corp., Armonk, NY). A two-tailed $p$ value of $<0.05$ was considered statistically significant.

\section{Results}

\section{Unintentional Injury}

As shown in Table 2, for the total sample, the most prevalent injuries were burns (18\%), followed by sprains/ fractures (17.3\%), animal bites (12.3\%), traffic accidents (5.5\%), and nonfatal drowning (4.2\%). 1534 children experienced at least one episode of injury, leading to $38 \%$ of the annual prevalence of unintentional injury.

Migrant children reported lower prevalence of sprains/ fractures ( 15.5 vs. $18.7 \%, p=0.007)$, but higher in animal bites ( 15.7 vs. $9.6 \%, p<0.001)$, burns (20.7 vs. $16 \%, p<$ 0.001 ), nonfatal drowning (6 vs. $2.7 \%, p<0.001$ ), and unintentional injury (40.9 vs. $35.7 \%, p<0.001)$.

\section{Mental Health Status, Substance Use Behavior and Parental Maltreatment}

Table 3 presents the features of psychosocial factors and their bivariate relationships with injury distribution. Children were divided into injured group and non-injured group. Compared with the non-injured, the injured were more likely to score higher in emotional symptoms (3.43 vs. 2.82, $p<0.001)$, conduct problems (2.60 vs. 2.07, $p<0.001)$, hyperactivity ( 4.08 vs. $3.29, p<0.001)$, peer problem $(2.86$ vs. $2.55, p<0.001)$, and lower in prosocial behavior $(6.94$ vs. $7.39, p<0.001)$, have suicide ideation ( 32.1 vs. $21.5 \%$, $p<0.001)$, currently smoke (1.3 vs. $0.6 \%, p=0.019)$, currently drink (4.7 vs. $2.7 \%, p=0.001)$, and be verbally maltreated (60.3 vs. $46.3 \%, p<0.001)$ and physically maltreated $(19.2$ vs. $11.7 \%, p<0.001)$ by parents.

\section{Associations with Unintentional Injury Prevalence}

Table 4 presents the results of the binary logistic regression. Nested models were employed to probe the potential associated factors to unintentional injury, including individual factors (child group, gender, age, mental health status, substance use behavior), school type, and family factors (family economic status, parents' education attainment, parents' marital status, and parental maltreatment).

In model 1, migrant children were more likely to experience unintentional injuries (Crude $\mathrm{OR}=1.24, p<0.001$ ), but this association was not significant because after controlling for other variables. In model 4 , the likelihood of unintentional injury was greater among male children $(\mathrm{OR}=1.45,95 \%$ $\mathrm{CI}=1.25-1.68)$, and significantly decreased with children's age $(\mathrm{OR}=0.93,95 \% \mathrm{CI}=0.88-0.98)$. In terms of SDQ subscale scores, we found that those with higher scores in emotional symptom $(\mathrm{OR}=1.07,95 \% \mathrm{CI}=1.03-1.12)$, conduct problem $(\mathrm{OR}=1.06,95 \% \mathrm{CI}=1.01-1.18)$ and hyperactivity $(\mathrm{OR}=1.07,95 \% \mathrm{CI}=1.03-1.12)$ were more likely to have experienced unintentional injuries. Children with suicide thoughts were 1.26 times more likely to suffer from unintentional injuries. Children in the migrant schools were more likely to report unintentional injuries $(\mathrm{OR}=1.31$,
Table 2 Annual prevalence of unintentional injuries by child migrant status

\begin{tabular}{lcllrr}
\hline & $\begin{array}{l}\text { Total } \\
n(\%) \\
(n=4036)\end{array}$ & $\begin{array}{l}\text { Urban } \\
n(\%) \\
(n=2266)\end{array}$ & $\begin{array}{l}\text { Migrant } \\
(\%) \\
(n=1770)\end{array}$ & $\chi^{2}$ & $P$-value \\
\hline Sprains/fractures & $698(17.3 \%)$ & $424(18.7 \%)$ & $274(15.5 \%)$ & 7.150 & 0.007 \\
Animal bites & $496(12.3 \%)$ & $218(9.6 \%)$ & $278(15.7 \%)$ & 34.23 & $<0.001$ \\
Burns & $726(18.0 \%)$ & $362(16.0 \%)$ & $364(20.7 \%)$ & 14.46 & $<0.001$ \\
Nonfatal drowning & $168(4.2 \%)$ & $62(2.7 \%)$ & $106(6.0 \%)$ & 26.59 & $<0.001$ \\
Traffic accidents & $223(5.5 \%)$ & $117(5.2 \%)$ & $106(6.0 \%)$ & 1.295 & 0.255 \\
Unintentional injury & $1534(38.0 \%)$ & $810(35.7 \%)$ & $724(40.9 \%)$ & 11.22 & 0.001 \\
\hline
\end{tabular}


Table 3 Relationship between unintentional injury and mental health status, substance use behavior and parental maltreatment

\begin{tabular}{|c|c|c|c|c|c|}
\hline & $\begin{array}{l}\text { Total } \\
n(\%) / \text { mean } \pm \mathrm{sd} \\
(n=4036)\end{array}$ & $\begin{array}{l}\text { Injured } \\
n(\%) / \text { mean } \pm \mathrm{sd} \\
(n=1534)\end{array}$ & $\begin{array}{l}\text { Non-injured } \\
n(\%) / \text { mean } \pm \mathrm{sd} \\
(n=2502)\end{array}$ & $\chi^{2} / t$ & $P$-value \\
\hline Emotional symptom & $3.05 \pm 2.07$ & $3.43 \pm 2.10$ & $2.82 \pm 2.01$ & 8.918 & $<0.001$ \\
\hline Conduct problem & $2.27 \pm 1.61$ & $2.60 \pm 1.68$ & $2.07 \pm 1.53$ & 9.986 & $<0.001$ \\
\hline Hyperactivity & $3.59 \pm 2.20$ & $4.08 \pm 2.18$ & $3.29 \pm 2.16$ & 11.12 & $<0.001$ \\
\hline Peer problem & $2.67 \pm 1.64$ & $2.86 \pm 1.66$ & $2.55 \pm 1.62$ & 5.944 & $<0.001$ \\
\hline Prosocial behavior & $7.22 \pm 2.08$ & $6.94 \pm 2.06$ & $7.39 \pm 2.08$ & -6.614 & $<0.001$ \\
\hline \multicolumn{6}{|l|}{ Suicide ideation } \\
\hline No & $2979(74.5 \%)$ & $1029(67.9 \%)$ & $1950(78.5 \%)$ & 55.92 & $<0.001$ \\
\hline Yes & $1021(25.5 \%)$ & $487(32.1 \%)$ & $534(21.5 \%)$ & & \\
\hline \multicolumn{6}{|l|}{ Current smoking } \\
\hline No & $3971(99.2 \%)$ & $1499(98.7 \%)$ & $2472(99.4 \%)$ & 5.466 & 0.019 \\
\hline Yes & $33(0.8 \%)$ & $19(1.3 \%)$ & $14(0.6 \%)$ & & \\
\hline \multicolumn{6}{|l|}{ Current alcohol use } \\
\hline No & $3850(96.5 \%)$ & $1440(95.3 \%)$ & $2410(97.3 \%)$ & 10.66 & 0.001 \\
\hline Yes & $139(3.5 \%)$ & $71(4.7 \%)$ & $68(2.7 \%)$ & & \\
\hline \multicolumn{6}{|l|}{ Verbal maltreated } \\
\hline Never & $1946(48.4 \%)$ & $607(39.7 \%)$ & $1339(53.7 \%)$ & 83.09 & $<0.001$ \\
\hline Occasionally & $1846(45.9 \%)$ & $798(52.2 \%)$ & $1048(42.0 \%)$ & & \\
\hline Often & $230(5.7 \%)$ & $123(8.1 \%)$ & $107(4.3 \%)$ & & \\
\hline \multicolumn{6}{|l|}{ Physical maltreated } \\
\hline Never & $3438(85.4 \%)$ & $1235(80.8 \%)$ & $2203(88.3 \%)$ & 45.57 & $<0.001$ \\
\hline Occasionally & $529(13.1 \%)$ & $259(16.9 \%)$ & $270(10.8 \%)$ & & \\
\hline Often & $58(1.4 \%)$ & $35(2.3 \%)$ & $23(0.9 \%)$ & & \\
\hline
\end{tabular}

95\% $\mathrm{CI}=1.06-1.63)$. Besides, children who were verbally maltreated by parents at home in the past year had greater odds (occasionally vs. never, $\mathrm{OR}=1.34, \quad 95 \% \quad \mathrm{CI}=$ 1.15-1.56; often vs. never, $\mathrm{OR}=1.40,95 \% \mathrm{CI}=1.00-1.96$ ) of experiencing unintentional injuries.

\section{Discussion}

The annual prevalence of unintentional injury among 5 to 9 grades schoolchildren in Yinzhou was revealed 38\%, which was higher than that in Europe (17.3\%) (Keyes et al. 2014), Canada (24\%) (Gilbride et al. 2006), and Jordan (33.9\%) (ALBashtawy et al. 2016), but lower than Yemen (48\%) (Alshahethi 2014) and Thailand (46.8\%) (Peltzer and Pengpid 2012). The prevalence was also higher than prior similar studies in China. Chen (Chen et al. 2005) reported an annual injury rate of $30.3 \%$ adolescents in Baise city, western China. Sun (Sun et al. 2006) found the occurrence of school injuries that resulted in medical attendance was $5.22 \%$ among primary and middle school students in Maanshan City, eastern China. Burn, sprains/fracture and animal bite were top three prevalent injuries, which was consistent with previous studies in Asia (Bhamkar et al. 2016; Li et al. 2013; Peltzer and Pengpid
2017). More importantly, we found migrant children were more likely to suffer from any unintentional injury and most of the specific injuries.

Considerable evidence has indicated the association between exogenous variables and injury. In accordance with previous studies (Fang et al. 2015; Hu et al. 2012), we found male and young age were positively associated with injury occurrence. Seemingly, family socioeconomic indicators were found not significantly correlated with injury occurrence in the adjusted regression model. Migrant children had a higher prevalence of unintentional injuries compared with the urban group, however, migrant status was found insignificant with unintentional injury according to the regression estimates in the total model, hence hypothesis 1 was partially confirmed. In spite of this, migration could be an important factor because it was closely related to other environmental factors. In the process of children's migration, with the change of residence, the environmental system they live in also changed dramatically, which means migration could have an indirect relationship with injury. The migrant children, especially the long-distance and interregional migrators from the midwest villages of China, are actually vulnerable population, for the few resources their families could motivate to cope with 
Table 4 Binary logistic regression model examining the correlates of unintentional injury $(n=4036)$

\begin{tabular}{|c|c|c|c|c|}
\hline & $\begin{array}{l}\text { Model } 1 \\
\text { OR }(95 \% \text { CI) }\end{array}$ & $\begin{array}{l}\text { Model } 2 \\
\text { OR (95\% CI) }\end{array}$ & $\begin{array}{l}\text { Model } 3 \\
\text { OR }(95 \% \text { CI) }\end{array}$ & $\begin{array}{l}\text { Model } 4 \\
\text { OR (95\% CI) }\end{array}$ \\
\hline Migrant status (ref $=$ urban) & $1.24(1.10,1.41)^{* * *}$ & $1.10(0.96,1.27)$ & $0.94(0.80,1.11)$ & $0.97(0.81,1.16)$ \\
\hline Gender $($ ref $=$ female $)$ & & $1.46(1.27,1.68)^{* * *}$ & $1.45(1.26,1.67)^{* * *}$ & $1.45(1.25,1.68)^{* * *}$ \\
\hline Age & & $0.91(0.87,0.96)^{* * *}$ & $0.92(0.88,0.97)^{* * *}$ & $0.93(0.88,0.98)^{* *}$ \\
\hline Emotional symptom & & $1.08(1.04,1.12)^{* * *}$ & $1.08(1.04,1.12)^{* * *}$ & $1.07(1.03,1.12)^{* * *}$ \\
\hline Conduct problem & & $1.07(1.02,1.13)^{* *}$ & $1.07(1.02,1.13)^{* *}$ & $1.06(1.01,1.18)^{*}$ \\
\hline Hyperactivity & & $1.09(1.04,1.13)^{* * *}$ & $1.08(1.04,1.13)^{* * *}$ & $1.07(1.03,1.12)^{* *}$ \\
\hline Peer problem & & $1.02(0.97,1.06)$ & $1.01(0.97,1.06)$ & $1.00(0.96,1.05)$ \\
\hline Prosocial behavior & & $0.99(0.95,1.02)$ & $0.99(0.95,1.03)$ & $0.99(0.95,1.03)$ \\
\hline Suicide ideation & & $1.34(1.13,1.58)^{* * *}$ & $1.33(1.13,1.57)^{* * *}$ & $1.26(1.06,1.49)^{* *}$ \\
\hline Current smoking $(\mathrm{ref}=\mathrm{no})$ & & $1.15(0.51,2.57)$ & $1.11(0.49,2.48)$ & $1.09(0.48,2.50)$ \\
\hline Current alcohol use $($ ref $=$ no) & & $1.25(0.85,1.83)$ & $1.24(0.84,1.82)$ & $1.09(0.73,1.62)$ \\
\hline School type $($ ref $=$ public school $)$ & & & $1.43(1.17,1.74)^{* * *}$ & $1.31(1.06,1.63)^{*}$ \\
\hline \multicolumn{5}{|l|}{ Family economic status $($ ref $=$ poor $)$} \\
\hline Fair & & & & $0.85(0.68,1.07)$ \\
\hline Wealthy & & & & $0.92(0.72,1.19)$ \\
\hline \multicolumn{5}{|c|}{ Parents' education attainment $($ ref $=$ illiteracy/primary school) } \\
\hline Middle school & & & & $0.90(0.70,1.16)$ \\
\hline High school & & & & $0.95(0.72,1.27)$ \\
\hline Junior college & & & & $0.88(0.61,1.28)$ \\
\hline Undergraduate and above & & & & $1.08(0.73,1.59)$ \\
\hline Parents' marital status ( $\mathrm{ref}=$ non-divorced $)$ & & & & $1.29(0.95,1.74)$ \\
\hline \multicolumn{5}{|l|}{ Verbal maltreatment $(\mathrm{ref}=\mathrm{no})$} \\
\hline Occasionally & & & & $1.34(1.15,1.56)^{* * *}$ \\
\hline Often & & & & $1.40(1.00,1.96)^{*}$ \\
\hline \multicolumn{5}{|l|}{ Physical maltreatment $(\mathrm{ref}=$ no $)$} \\
\hline Occasionally & & & & $1.15(0.93,1.42)$ \\
\hline Often & & & & $1.24(0.63,2.46)$ \\
\hline Constant & 0.556 & 0.803 & 0.721 & 0.723 \\
\hline$\chi^{2}$ & 11.20 & 216.3 & 228.2 & 240.6 \\
\hline $\mathrm{P}$ & $<0.001$ & $<0.001$ & $<0.001$ & $<0.001$ \\
\hline
\end{tabular}

OR odds ratio, $95 \%$ CI $95 \%$ confidence interval

$* p<0.05 ; * * p<0.01 ; * * * p<0.001$

discomfort with language, social connections with urban children, and urban norms (Sun et al. 2016). Our results had shown that the migrant group was disadvantaged in family socioeconomic status, which was in line with previous studies (Gao et al. 2017; Luo and Zhang 2017). Another noticeable finding was that school type was an independent predicting factor for unintentional injury. In the survey sample we found that an overwhelming majority of urban children came from public schools, whilst nearly one half of the migrant children were attending migrant children school with relatively insufficient financial resources, poorer infrastructure, and less-qualified teachers (Liang 2016). To make matters worse, these teachers' work was characterized by low pay, long hours, high work intensity, and lack of job security (Friedman 2017) so that they could hardly take good care of the students, which might in turn jeopardize the students' psychological well-being and expose them in the risk of danger (Lu and Zhou 2013; X. Sun et al. 2016).

Our findings confirmed that emotional symptoms, conduct problems and hyperactivity were significantly associated with unintentional injury, which was demonstrated by prior studies (Keyes et al. 2014; Lalloo et al. 2003). Lalloo reported that English children who scored high for emotional symptoms and hyperactivity were 1.5 times more likely to report minor accidents (Lalloo et al. 2003). A survey across 7 European regions suggested that mother-reported internalizing problems (scores above the cut-point of emotional problems, hyperactivity, and conduct problems) were associated with 
unintentional injury (Keyes et al. 2014). A possible mechanism for these associations could be a stronger propensity among these children to engage in potentially injury-inducing behavior such as fighting with schoolmates (Peltzer and Pengpid 2017), stimulating in dangerous activities (Steinberg et al. 2008), and disregarding public rules. Further, suicide ideation was highly associated with injury incidence, the outcome was also previously found (Peltzer and Pengpid 2012, 2017).

Much of the literature has documented the predictive value of substance use behavior including smoking, drinking and marijuana use on injury (Asbridge et al. 2014; Peltzer 2008; Peltzer and Pengpid 2012). Though significant difference was observed in smoking and alcohol use behavior between injured and non-injured groups, the correlations were explained by socio-demographic and other predicting risk factors in the regression analysis. The reason could be attributed to the strict prohibition of selling cigarettes and wine to juveniles in retailing, therefore children couldn't easily get access to these substances in everyday life, which was implied by the low prevalence of smoking and drinking behavior among the sample. Further studies in China should incorporate more specific items to investigate children's substance use behavior in magnitude and frequency.

Additionally, we found parental verbal maltreatment a contributing factor in unintentional injury. Rough parenting style might have underlying psychopathology or higher levels of hostility, creating an environment where acting out and risk-taking by the children are more likely (Keyes et al. 2014). Abused and neglected children were more susceptible to behavioral and emotional difficulties (McGloin and Widom 2001). Critically, child maltreatment was significantly more common in the lower social classes. A survey conducted in Shenzhen reported migrant adolescents were 1.49 and 1.425 times more likely to be psychologically and physically abused by their parents than their local counterparts (Gao et al. 2017).

In this study, we provided a socio-ecological framework which integrated children's individual characteristics and environmental factors. Based on the original model, the multi-level psychosocial factors introduced had enhanced the explanatory power in steps. According to the total model, hypothesis $2 \mathrm{a}$ and $2 \mathrm{c}$ were partly confirmed, while hypothesis $2 \mathrm{~b}$ was confirmed. The total model was comprehensive and concise, and had shown its potential as a feasible analytical framework in similar studies.

The global injury control community has for many years believed that: most injuries are preventable (Tan et al. 2014). This study sheds further light on the need to react to the serious situation of unintentional injury morbidity among Chinese school children, the findings informed a number of implications for prevention strategies in urban area. Special financial subsidy toward migrant children schools could be considered to enhance their teaching infrastructure and encourage the collaboration with professional organizations such as CDC and women's federation to introduce novel educational and behavioral training programs against child injury into curriculum (S. Liu et al. 2016). Meanwhile, mental health services for students such as psychological counseling could be put into practice (Chen et al. 2005). At the community level, community police, neighborhood committee and voluntary sectors should intensify community patrol to help children timely who are maltreated by parents. As regard to the academia of public health, past injury prevention studies in China mainly emphasize educational interventions. Exploration on the effectiveness and synergy of non-education interventions such as law enforcement, environmental and engineering interventions which aimed to alter the physical environment or modify the design of safety devices could be a major direction in the future (He et al. 2014).

\section{Limitations}

Several limitations exist in this study. First, the preciseness of this study was limited to the relatively simple measurements. With the restrictions of time and resources, we just took the crude prevalence of unintentional injury as the main outcome variable, whilst more detailed epidemiological information about the injuries such as place, time, and frequency was lacking. The homothetic situation could be found in the measurement of smoking and alcohol use behavior and child maltreatment. Besides, drug use was not included in the behavioral factors of substance use. Second, the survey employed a self-conducted questionnaire, which might lead to recall bias from the respondents. Third, the study was a cross-sectional approach; therefore we couldn't ascribe causality to the significantly associated factors. Finally, our sample was limited to a county level area in the Southeast, the findings are unable to be generalized to the whole child population across China.

\section{Data Availability}

The data-sets analyzed during this study are available from the corresponding author on reasonable request.

Acknowledgements We thank the 13 participant schools for their approvals for the survey. We also thank Yinzhou CDC for supporting the coordination.

Funding This study was funded by Zhejiang University Zijin Talent Programme (2015). Neither the funder of the study nor any of the participant organizations influenced the research design, data analysis and data interpretation. 
Author Contributions Chao Gao conducted the statistical analysis and drafted the manuscript. Pengfei Chai organized the field survey. Jingjing Lu participated in the statistical analysis. Hongmei Wang revised the manuscript. Lu Li and Xudong Zhou together conceived and designed the critical framework of the study, and coordinated the field survey. All the authors have read and approved the final manuscript.

\section{Compliance with Ethical Standards}

Conflict of Interest The authors declare that they have no conflict of interest.

Informed Consent Verbal agreement to participate was obtained from all individual participants included in the study.

Publisher's note: Springer Nature remains neutral with regard to jurisdictional claims in published maps and institutional affiliations.

Open Access This article is distributed under the terms of the Creative Commons Attribution 4.0 International License (http://crea tivecommons.org/licenses/by/4.0/), which permits use, duplication, adaptation, distribution, and reproduction in any medium or format, as long as you give appropriate credit to the original author(s) and the source, provide a link to the Creative Commons license, and indicate if changes were made.

\section{References}

ALBashtawy, M., Al-Awamreh, K., Gharaibeh, H., Al-Kloub, M., Batiha, A. M., Alhalaiqa, F., \& Hamadneh, S. (2016). Epidemiology of Nonfatal Injuries Among Schoolchildren. J Sch Nurs, 32(5), 329-336. https://doi.org/10.1177/1059840516650727.

Alshahethi, A. H. A. (2014). Unintentional injuries among 9 to 12 grades schoolchildren in Sana'a Capital City, Yemen, 2012. International Journal of Infectious Diseases, 21, 253-253. https://doi.org/10.1016/j.ijid.2014.03.947.

Ameratunga, S., \& Peden, M. (2009). World report on child injury prevention: a wake-up call. Injury, 40(5), 469-470.

Asbridge, M., Azagba, S., Langille, D., \& Rasic, D. (2014). Elevated depressive symptoms and adolescent injury: examining associations by injury frequency, injury type, and gender. BMC Public Health, 14, 190.

Bhamkar, R., Seth, B., \& Setia, M. S. (2016). Profile and Risk Factor Analysis of Unintentional Injuries in Children. Indian Journal of Pediatrics, 83(10), 1114-1120. https://doi.org/10.1007/s12098016-2159-2.

Bronfenbrenner, U. (1979). The Ecology of Human Development: Experiments by Nature and Design. Cambridge, Massachusetts: Harvard University Press.

Chandran, A., Hyder, A. A., \& Peek-Asa, C. (2010). The global burden of unintentional injuries and an agenda for progress. Epidemiologic Reviews, 32, 110-120. https://doi.org/10.1093/ epirev/mxq009.

Chen, G., Smith, G. A., Deng, S., Chen, D., Kelleher, K., \& Xiang, H. (2005). Psychological symptoms and nonfatal unintentional injuries among Chinese adolescents: a prospective study. Journal of Adolescent Health, 37(6), 460-466. https://doi.org/10.1016/j.ja dohealth.2004.09.005.

Chen, Y., \& Feng, S. (2017). Quality of migrant schools in China: evidence from a longitudinal study in Shanghai. Journal of Population Economics, 30(3), 1007-1034. https://doi.org/10. 1007/s00148-016-0629-5. de Ramirez, S. S., Hyder, A. A., Herbert, H. K., \& Stevens, K. (2012). Unintentional injuries: magnitude, prevention, and control. Annu Review of Public Health, 33(1), 175-191. https://doi.org/10. 1146/annurev-publhealth-031811-124558.

Du, Y., Kou, J., \& Coghill, D. (2008). The validity, reliability and normative scores of the parent, teacher and self report versions of the Strengths and Difficulties Questionnaire in China. Child Adolesc Psychiatry Ment Health, 2(1), 8. https://doi.org/10.1186/ 1753-2000-2-8.

Fang, Y., Zhang, X., Chen, W., Lin, F., Yuan, M., Geng, Z., \& Dai, L. (2015). Epidemiological characteristics and burden of childhood and adolescent injuries: a survey of elementary and secondary students in Xiamen, China. BMC Public Health, 15, 357. https:// doi.org/10.1186/s12889-015-1726-1.

Feng, W., Gong, Q., Liu, K., \& Li, H. (2017). Analysis of Behavioural Characteristics Related to Unintentional Injury in Southeast Chinese Adolescents: Evidence from a School-Based Survey. Int J Environ Res Public Health, 14(3). https://doi.org/10.3390/ ijerph14030241.

Friedman, E. (2017). Teachers' Work in China's Migrant Schools. Modern China, 43(6), 559-589. https://doi.org/10.1177/ 0097700417703657.

Gao, Y., Atkinson-Sheppard, S., \& Liu, X. (2017). Prevalence and risk factors of child maltreatment among migrant families in China. Child Abuse \& Neglect, 65, 171-181. https://doi.org/10.1016/j. chiabu.2017.01.023.

Gilbride, S. J., Wild, C., Wilson, D. R., Svenson, L. W., \& Spady, D. W. (2006). Socio-economic status and types of childhood injury in Alberta: a population based study. BMC Pediatrics, 6, 30. https://doi.org/10.1186/1471-2431-6-30.

Goodman, R. (1997). The Strengths and Difficulties Questionnaire: A research note. Journal of Child Psychology and Psychiatry and Allied Disciplines, 38(5), 581-586. https://doi.org/10.1111/j. 1469-7610.1997.tb01545.x.

Goodman, R., Meltzer, H., \& Bailey, V. (1998). The Strengths and Difficulties Questionnaire: a pilot study on the validity of the selfreport version. European Child \& Adolescent Psychiatry, 7(3), 125-130.

He, Q., Kang, W., Tian, D., Huang, Y., Gao, L., Deng, X., \& Hu, G. (2014). Analysis of the quantity and quality of published randomised controlled trials related to injury prevention from 2001 to 2010 in China. Injury prevention, 20(3), 148-154. https://doi.org/ 10.1136/injuryprev-2013-040843.

Hu, G. Q., \& Baker, S. P. (2009). Trends in Unintentional Injury Deaths, US, 1999-2005 Age, Gender, and Racial/Ethnic Differences. American Journal Of Preventive Medicine, 37(3), 188-194. https://doi.org/10.1016/j.amepre.2009.04.023.

Hu, H., Gao, J., Jiang, H., \& Xing, P. (2018). A comparative study of unintentional injuries among schooling left-behind, migrant and residential children in China. International journal for Equity in Health, 17(1), 47. https://doi.org/10.1186/s12939-018-0767-3.

Hu, M., Hu, G. Q., Sun, Z. Q., \& He, X. (2012). Epidemiological survey of the prevalence of non-fatal injury among children aged 5-14 years in China. Biomedical and Environmental Sciences, 25 (4), 407-412. https://doi.org/10.3967/0895-3988.2012.04.005.

Hyder, A. (2009). Global childhood unintentional injury surveillance in four cities in developing countries: a pilot study. Bulletin of the World Health Organization, 87(5), 345-352. https://doi.org/10. 2471/blt.08.055798.

Ji, Y., Wang, Y., Sun, L., Zhang, Y., \& Chang, C. (2016). The migrant paradox in children and the role of schools in reducing health disparities: a cross-sectional study of migrant and native children in Beijing, China. PLoS ONE, 11(7), e0160025. https://doi.org/ 10.1371/journal.pone.0160025.

Jin, H., Hua, J., Shen, J., Feng, L., \& Gu, G. (2016). Status and Determinants of Motor Impairment in Preschool Children from 
Migrant Families in China. Iranian Journal of Pediatrics, In Press(In Press). https://doi.org/10.5812/ijp.5427.

Keyes, K. M., Susser, E., Pilowsky, D. J., Hamilton, A., Bitfoi, A., Goelitz, D., \& Kovess, V. (2014). The health consequences of child mental health problems and parenting styles: unintentional injuries among European schoolchildren. Preventive MedicinePrev Med, 67, 182-188. https://doi.org/10.1016/j.ypmed.2014. 07.030 .

Kou, J. H., Du, Y. S., \& Xia, L. M. (2007). Formulation of children strengths and difficulties questionnaire (the edition for students) for Shanghai norm. China Journal of Health Psychology, 15, $3-5$.

Kumar, R., Bhave, A., Bhargava, R., \& Agarwal, G. G. (2013). Prevalence and risk factors for neurological disorders in children aged 6 months to 2 years in northern India. Developmental Medicine and Child Neurology, 55(4), 348-356. https://doi.org/ 10.1111/dmcn.12079.

Lalloo, R., Sheiham, A., \& Nazroo, J. Y. (2003). Behavioural characteristics and accidents: findings from the Health Survey for England, 1997. Accident Analysis \&. Prevention, 35(5), 661-667. https://doi.org/10.1016/s0001-4575(02)00044-1.

Li, S., Tang, Z., Zhang, X., Yan, L., Wang, S., Liu, G., \& Sun, Y. (2013). Epidemiologic features of child unintentional injury in rural PuCheng, China. Journal of injury \& Violence Research, 5 (2), 89-94. https://doi.org/10.5249/jivr.v5i2.304.

Liang, Z. (2016). China's Great Migration and the Prospects of a More Integrated Society. Annual Review of Sociology, 42(1), 451-471. https://doi.org/10.1146/annurev-soc-081715-074435.

Liu, D., Yu, X., Wang, Y., Zhang, H., \& Ren, G. (2014). The impact of perception of discrimination and sense of belonging on the loneliness of the children of Chinese migrant workers: a structural equation modeling analysis. International Journal of Mental Health Systems, 8. https://doi.org/10.1186/1752-4458-8-52.

Liu, S., Hu, M., Chang, Y., Chen, H., \& Tu, J. (2016). [Meta analysis for interventional effect on unexpected injury among children and adolescents in China]. Zhong Nan Da Xие Xие Bao Yi Xue Ban, 41(5), 527-533. https://doi.org/10.11817/j.issn.1672-7347.2016. 05.013.

Lozano, R., Naghavi, M., Foreman, K., Lim, S., Shibuya, K., Aboyans, V., \& Murray, C. J. L. (2012). Global and regional mortality from 235 causes of death for 20 age groups in 1990 and 2010: a systematic analysis for the Global Burden of Disease Study 2010. Lancet, 380(9859), 2095-2128.

Lu, Y., \& Zhou, H. (2013). Academic Achievement and Loneliness of Migrant Children in China: School Segregation and Segmented Assimilation. Comparative Education Review, 57(1), 85-116. https://doi.org/10.1086/667790.

Luo, F., \& Zhang, Y. (2017). Probing the SES-achievement connection in the fast-changing society of China: a comparison of urban, rural, and migrant students. Asia Pacific Education Review, 18(1), 101-113. https://doi.org/10.1007/s12564-017-9472-y.

McGloin, J. M., \& Widom, C. S. (2001). Resilience among abused and neglected children grown up. Development and Psychopathology, 13(4), 1021-1038. https://doi.org/10.1017/s095457940100414x.

Mellor, D., Cheng, W., McCabe, M., Ling, M., Liu, Y., Zhao, Z., \& $\mathrm{Xu}, \mathrm{Y}$. (2016). The use of the SDQ with Chinese adolescents in the clinical context. Psychiatry Research, 246, 520-526. https:// doi.org/10.1016/j.psychres.2016.10.034.

Peltzer, K. (2008). Injury and social determinants among in-school adolescents in six African countries. Injury Prevention, 14(6), 381-388. https://doi.org/10.1136/ip.2008.018598.

Peltzer, K., \& Pengpid, S. (2012). Injury and social correlates among in-school adolescents in four Southeast Asian countries. International Journal of Environmental Research and Public Health, 9(8), 2851-2862. https://doi.org/10.3390/ijerph9082851.
Peltzer, K., \& Pengpid, S. (2017). Nonfatal Injuries and Psychosocial Correlates among Middle School Students in Cambodia and Vietnam. International Journal of Environmental Research and Public Health, 14(3), pii: E280. https://doi.org/10.3390/ ijerph14030280.

Schwartz, S. J., Unger, J. B., Zamboanga, B. L., \& Szapocznik, J. (2010). Rethinking the concept of acculturation implications for theory and research. American Psychologist, 65(4), 237-251. https://doi.org/10.1037/a0019330.

Simpson, K., Janssen, I., Craig, W. M., \& Pickett, W. (2005). Multilevel analysis of associations between socioeconomic status and injury among Canadian adolescents. Journal Of Epidemiology And Community Health, 59(12), 1072-1077. https://doi.org/10. 1136/jech.2005.036723.

Sleet, D. A., Ballesteros, M. F., \& Borse, N. N. (2010). A review of unintentional injuries in adolescents. Annual Review of Public Health, 31, 195-212. https://doi.org/10.1146/annurev.publhealth. 012809.103616.

Spady, D., Saunders, D., Schopflocher, D., \& Svenson, L. (2004). Patterns of injury in children: a population-based approach. Pediatrics, 113(3 Pt 1), 522-529.

Steinberg, L., Albert, D., Cauffman, E., Banich, M., Graham, S., \& Woolard, J. (2008). Age differences in sensation seeking and impulsivity as indexed by behavior and self-report: evidence for a dual systems model. Developmental Psychology, 44(6), 1764-1778. https://doi.org/10.1037/a0012955.

Stokols, D. (1992). Establishing and maintaining healthy environments: Toward a social ecology of health promotion. American Psychologist, 47(1), 6-22. https://doi.org/10.1037/0003-066x.47.1.6.

Sun, X., Chen, M., \& Chan, K. L. (2016). A meta-analysis of the impacts of internal migration on child health outcomes in China. BMC Public Health, 16, 66. https://doi.org/10.1186/s12889-0162738-1.

Sun, Y., Yu, I., Zhang, Y., Fan, Y., Guo, S., \& Wong, T. (2006). Unintentional injuries among primary and middle school students in Maanshan City, eastern China. Acta Paediatrica, 95(3), 268-275.

Tan, A., Zhang, X., Baker, S. P., \& Hu, G. (2014). How do public health practitioners in China perceive injury prevention? A survey. Injury Prevention, 20(3), 196-199. https://doi.org/10.1136/ injuryprev-2012-040724.

Wang, J. N., Liu, L., \& Wang, L. (2014). Prevalence and associated factors of emotional and behavioural problems in Chinese school adolescents: a cross-sectional survey. Child: Care, Health and Development, 40(3), 319-326. https://doi.org/10.1111/cch.12101.

Wang, S., Li, Y., Chi, G., Xiao, S., Ozanne-Smith, J., Stevenson, M., \& Phillips, M. (2008). Injury-related fatalities in China: an underrecognised public-health problem. Lancet, 372(9651), $1765-1773$.

WHO. (2008). World Health Statistics 2008. Retrieved Sep 17, 2018, from http://www.who.int/gho/publications/world_health_statistics/ 2008/en/.

Xiaoli, Y., Chao, J., Wen, P., Wenming, X., Fang, L., Ning, L., \& Guowei, P. (2014). Prevalence of psychiatric disorders among children and adolescents in northeast China. PLOS ONE, 9(10), e111223. https://doi.org/10.1371/journal.pone.0111223.

Xu, H., \& Xie, Y. (2015). The Causal Effects of Rural-to-Urban Migration on Children's Well-being in China. European Sociological Review, 31(4), 502-519. https://doi.org/10.1093/esr/ jev009.

Yao, S., Zhang, C., Zhu, X., Jing, X., McWhinnie, C. M., \& Abela, J. R. (2009). Measuring adolescent psychopathology: psychometric properties of the self-report strengths and difficulties questionnaire in a sample of Chinese adolescents. Journal of Adolescent Health, 45(1), 55-62. https://doi.org/10.1016/j.jadohealth. 2008.11.006. 
Yin, Z., Wu, J., Luo, J., Pak, A. W., Choi, B. C., \& Liang, X. (2015). Burden and trend analysis of injury mortality in China among children aged 0-14 years from 2004 to 2011. BMJ Open, 5(7), e007307. https://doi.org/10.1136/bmjopen-2014-007307.
Yue, Z., Li, S., Jin, X., \& Feldman, M. W. (2013). The role of social networks in the integration of chinese rural-urban migrants: a migrant-resident tie perspective. Urban Studies, 50(9), 1704-1723. https://doi.org/10.1177/0042098012470394. 